\title{
Program-target methods of management small business
}

\author{
Ekaterina Gurova ${ }^{1, *}$ Tatyana Larinina $^{1}$, Nikita Zakorin $^{2}$,Larisa Andreeva ${ }^{3}$, and Lyubov \\ Manukhina $^{4}$ \\ ${ }^{1}$ Vyatka State University, Moskovskaya str., 36, Kirov, 610000, Russia \\ ${ }^{2}$ Baltic Academy of tourism and entrepreneurship, Petrozavodskaya str., 13, lit. A, Saint-Petersburg, \\ 191144, Russia \\ ${ }^{3}$ Moscow people's friendship University, Ordzhonikidze str., Moscow, 129300, Russia \\ ${ }^{4}$ Moscow State University of Civil Engineering, Yaroslavskoe shosse, 26, Moscow, 129337, Russia
}

\begin{abstract}
Experience of small businesses in Russia are just beginning their path to development. difficulties arise with the involvement of small businesses in the implementation of government development programmes. Small business in modern conditions to secure a visible prospect of development without the implementation of state support programmes. Ways and methods of regulation of development of the market economy are diverse. The total mass of the huge role is played by the program-target methods of regulation. The article describes the basic principles on the use of program-target approach to the development of a specific sector of the economy, as small businesses, designed to play an important role in getting the national economy out of crisis. The material in this publication is built from the need to maintain the connection between the theory of government regulation, practice of formation of development programs at the regional level and the needs of small businesses. Essential for the formation of entrepreneurship development programmes is to preserve the flexibility of small businesses in making management decisions related to the selection and change of activities.
\end{abstract}

\section{Introduction}

The development of principles, methods and instruments of management in the sphere of small business (MP) is a continuous, permanent. They are constantly being improved and modified as and when the society new socio-economic challenges. The practical implementation of a comprehensive, systematic approach to the solution of specific problems in the development of the MP require formation of special systems of interconnected and interdependent activities aimed at achieving specific socio-economic objectives. Control method, providing for their formation and the organization called the program-target method.

*Corresponding author: yesgurova@gmail.com 


\section{Methods}

The ideological basis of the development trust approach is the creation of Peter Drucker (Peter F. Drucker) the concept of "Management by objectives" (Management Objectives $\mathrm{Wu}$ - CVM), which he outlined in his book ancient The Practice of Management $\gg$ (1954). The practical implementation oriented approach by P. Drucker put it in the system of KPI (Key Performance Indicators) or KPIs. A handy tool widely used in business, including in Russia. Speaking about the target approach, it should be understood that "the goal is a concrete state of individual characteristics of the organization, the achievement of which it is desirable and towards which directed its activities" [1-5]. In management one of the main functions is the process of determining the purpose. It should be understood that this function is anticipatory in nature and is the stage of preliminary control, which largely determines the content characteristic further action [3,4,5-11].

Currently, there are several approaches to the presentation of the General concept of program management and methodological foundations of the use it to control MP. Development of teoretiko-methodological bases of program and target planning and management, search mechanisms for its effective application in public development engaged in such scientists as Yu. Alekseev, A. N. Alisov, G. V. Atamanchuk, A. M. Bredihin, V. N. Burkov, A. J.L. Gaponenko, B. Danev, A. B. Doktorovich, A. K. Enaleev, V. A. Irikov, N. And. Komkov, V. V. Kondrat'ev, and M. T. French.

With a narrow interpretation of the programmno-target management small business covers only the software aspect in planning the development of MP, i.e. the formation and organization of complex programmes at all levels and in all business units, those forecasting business activities [6-9,12-16]. In this case, target-oriented management reflects a new, a software aspect in the control system along with the traditional industry, functional and territorial aspects. With broad interpretation, the target-oriented approach is considered as the methodological basis of improving the management of scientific and technological progress in modern conditions. First and foremost, the implementation of program-target approach is reflected in the content, methods and technology of performing the scheduled calculations of the development of MP.

Analysis of existing complex programs and methods of their development suggests that the goal in some cases is identified with the other, close to it concepts, or with the means of achieving it $[7,10,13,15]$. Due to methodological discrepancies as the goal of the program is often one of the target functions. Such an objective deprives a comprehensive program of original meaning, consisting in the choice and as the object of program-target methods exclusively cross-functional tasks which are difficult with existing facilities. Functional same purpose, as a rule, standard, are programmed by nature and cannot serve as the starting point for the development of the center.

On the other hand, often as targets for the development programme of MP put forward a solution, such tasks as "the most complete satisfaction of needs of the enterprises MB", "MP", "social development" etc. without denying the validity of setting such goals, however one trait they do not allow to qualify them as a starting point of building a DC, they may not be quantifiable and, therefore, be considered as goals of the program.

The essence of the program-target management is that it allows you to implement when designing programs for the logic of planning "from", from final results and provides training for each of the identified issues comprehensive program of its decision.

Actually, the term "targeted approach" defines the specific features of the method:

- the definition of "software" - selects a new item in the planning system, reflecting the scale and complexity of problem solving; 
- the definition of "target" - describes the focus of the planning process emphasizes structural and functional hierarchy of development plans of MP to the solution of problems of social and economic development.

Management tasks in software-oriented approach are established on the basis of carefully designed levels of the management hierarchy of objectives, by combining both aspects - resource and the target.

The planning process begins with the formation of the hierarchy, the General development objectives (task stage), passes through a stage of education cross-cutting programs to ensure the achievement of established development objectives (program phase); and ends with the development plan and the allocation of resources in the form of a policy of balanced tasks for the structural elements of the system for a specific period (the planning stage).

The objective of the task stage is the formation and justification of the list of the most important interrelated objectives for implementation which should be directed to cash resources. Clear target orientation plans of small enterprises in the conditions of implementation of program-target approach is that at the first stage of their training, the developers must follow from the assessment of the potential of production in the industry and challenge it to increase.

\section{Results}

The contents of the second software stage of planning is creating a set of interrelated scientific, technical and industrial activities in programs, ensuring the achievement of established development goals MP. The objective of this stage is to choose the best path, providing a comprehensive solution of specific tasks at minimum cost and in the shortest possible time.

Harmonization and alignment of the entire set of programs within the limited resources for individual prospective periods is the content of the third stage resource calculations. The objective of this stage is to prepare a long-term, prospective and current plans of resource allocation for individual programs, and the establishment of integrated development indicators for the structural elements of the system.

In General, the work on formation of programs of development of the MP should be repeated several times in the iterations in the loop, "goal - program - resources" or in its separate parts (for example, "the goal of a programme-objectives and resources-programresources").

The iterative cycle of preparation of the development plans of MP should be transparent, that is to be implemented when planning the development of the economy in General in the ministries and Federal agencies, constituent entities of the Russian Federation and directly to enterprises in accordance with the scheme shown in figure 1.

On the first level, on the basis of pre-set General goals for the development of the economy, calls for the preparation of major development programs of the MP and establishment of composite indicators at the Federal level, acting as targets for the formation of economic policy in certain regions and sectors of the economy.

On the second level, provides for the preparation of sectoral or regional governments of internal development programmes and the establishment of integrated indicators of development of the MP for their subordinate enterprises.

At the third level the enterprises and the organization of its form in accordance with consolidated figures for their own long-term development program of the MP. As a starting point for the planned calculations carried out at the industry level using aggregate indicators, and state plans for the development of MP. 


\section{Discussion}

Sets out the planning scheme provides the requirement of strengthening the centralized management of processes of creation and development of small enterprises, while maintaining at the same time full freedom in determining economic policies for specific elements of the system MP.

In the use of various forms of partnership between government and business is the practice of using administrative contracts (relations), which laid down reciprocal obligations of the Contracting parties.

However, in recent times representatives of the business community and population exhibit a number of initiatives of public value outside the contractual relationship. This kind of initiative forms, which can also be realizable in the second level inter-municipal relationships, in particular, to include crowdsourcing (from the English. the "crowd" - the crowd, the people, the "source" - the source), implemented in the form of local community initiatives, as well as some form of application of the method of interactive planning in the development of the territories in which the crucial role of the initiators and executors of decisions of the representatives of the local business community (in the POI including social entrepreneurship) and the population. The main tasks solved by these approaches, in particular:

- various projects of the formation of network products, such as information, like Wikipedia, and communication in various social networks, as well as the service of providing goods and services in the field of electronic Commerce;

- discussion of legislative initiatives and various local projects on Internet forums;

- the formation of public opinion in the development of strategic development documents of regions and municipalities (in the form of discussion and elaboration of proposals for strategic documents in the context of the provisions of the new Federal law "On strategic planning in the Russian Federation (№ 172-FZ of 28.06.2014);

- collect complaints and suggestions on the work of individual sectors of municipal services (transport, housing and communal complex, development of the urban areas, organization of socio-cultural services, etc.);

- to evaluate the results of activities of Executive authorities and heads of administrativeterritorial units and the units responsible for the service infrastructure, etc.

The third level of partnership appropriate to classify forms of interaction between the territorial and administrative structures in their various combinations.

Certain preconditions for the development of various forms of such cooperation were established with the introduction of the "guidelines for the inter-regional and intermunicipal cooperation in the sphere of implementation of expenditure powers and local issues".

The main purpose of these recommendations was to facilitate:

- strengthening of interregional economic linkages and development of local markets for goods and services;

- optimization of processes of formation of the infrastructure on the basis of cooperation activities of the various administrative territories to strengthen the possibility of using the services of entities with shared infrastructure;

- budgetary savings by minimizing duplication of the same type of constituent entities of the infrastructure belonging to different municipalities;

- implement large-scale investment projects, including in the field of service infrastructure that is only possible with the integration of resources interacting agents belonging to different municipalities and other local issues.

Since the main deterrent to implementation in the municipalities of the complex local issues, carried out primarily through the provision of public services, is the budget deficit of 
local governments and lack of material resources, required to raise additional funds to address these tasks, one of the sources which can be inter-territorial projects and communication [5,14-17].

The practice of using the Russian legislation in the sphere of inter-municipal cooperation, the partners of which are bodies of local self-government of municipal formations of various types, indicates the use of three main forms of partnership:

- education councils and other associations of municipalities (associations, unions, etc.);

- conclusion of agreements on cooperation, joint activity in solving problems of local importance on the territory of interacting municipalities;

- creation of economic (commercial) and nonprofit (voluntary) intermunicipal organizations.

One of the most common organizational-legal forms of intermunicipal cooperation, such as the formation of municipal associations (unions) that performs a wide range of functions (from the joint submission and lobbying of interests of participants of such partnership prior to the organization of economic interaction in the market of production and realization of competitive goods and services).

Thus, targeted control ensures the timely detection of the most important tasks of the development of MP in General, the formation of a complex of interrelated measures aimed at solving priority and to ensure balanced this event with all necessary resources.

Practice has shown that the structuring purposes it is necessary to distinguish between two varieties: functional and problematic. When structuring any problems MP first sets of the functional elements, which are the condition of complete and integrated it solutions. The tool of such a functional structuring of the problem in the development of programs is the "tree of objectives". The latter is a hierarchical system with several levels, which are consistently detailed objectives that require implementation. Thus, the objectives of each subsequent level should provide the realization of the goals of the level above. The construction of "objectives tree", i.e., sequential splitting of the final objectives of the programme into its constituent elements, is not based on a formal dependency, and the use of primarily expert experts.

"Tree of objectives" of the programme sectoral level, as well as design for small businesses may be limited to five or six levels. For example, in development programmes, the MP can include the following signs division:

- the "O" identifies the ultimate goal and the conditions of implementation of the program as a whole;

- at the level "1" specified sub-goal development of MP in each of the segments of the planning period;

- in level "2" may be a broad alternative approaches to achieving the goal. At this level, sets the objectives and alternatives of development of the MP;

- level "3", examines the challenges and resources of development of the MP (raw materials, equipment, technological processes);

- at level "4" are formed of tasks of development of individual processes, methods of development of SP required to obtain the most important components of the elements of the level "Z";

- on level 5 of the hierarchy are the objectives and alternatives for the development of functional elements of a control system of the MP, providing challenges to elements of the preceding level.

When you build a "tree of objectives" at the beginning sets the overall composition of the elements for each of the selected hierarchical levels. At the same time, taken into consideration and existing, utilized items and items developed. 
The list includes required and alternative elements. Each of them is a limited list of key target indicators of its potential and revealing the contents of targets of elements of the level above.

In determining the target values should be based on the need for compulsory maintenance of target parameters corresponding element of the level above. In addition to the targets for each of the elements of the "tree of objectives" is recommended to set the limiting parameters that determine special conditions for the achievement of goals.

The composition of these parameters and their value are selected and justified by experts based on the specifics of the program itself. Limiting the set of requirements that necessarily must be sustained under the implementation of the program.

\section{Conclusions}

Be aware that the bounding parameters established new conditions for the achievement of targets, thereby dramatically reducing the number of possible solutions to the problem, i.e. finding the bounding part of the program parameters and their quantitative values can be considered as first and most integrated feasibility study development of a variant of implementation of the program.

The necessary stage of development, CPU development, MP is the rationale and the calculation of financial expenses for its implementation. Among the significant diversity of the methods of these calculations the most widely standard method the essence of which is the feasibility study of the program activities using the standards. Thus, under the rules understand science-based measure of consumption of the resource, and under the regulations - the extent of use of these resources mentioned, usually in relative form. With their help settle important proportions in the use of material, labor, energy, financial and other resources required to execute the planned activities. In turn, these relations are used to determine financial costs for the implementation of planned activities. The totality of these norms and standards and the increasing use for economic development program planning determine the need of an automated system of collection, accumulation and updating rules and regulations, which generally include a set of reasonable rules and regulations, procedure and methods of their formation, update and use when carrying out the corresponding calculations. When the program-target planning uses the integrated standards and regulations. In current practice, norms and standards are determined in various ways. The most perfect is settlement-analytical method of calculation, which involves the definition of norms and specifications based on technical and economic calculations. In cases when there is no possibility of application of calculating and analytical method, rules and regulations are determined on the basis of accounting and statistical data for previous periods. The use of this method in the calculations is undesirable due to its inherent deficiencies as expressed in the use of "obsolete" data, not taking into account new scientific and technical achievements and the possibility of using reserves. Along with the calculation methods for the formation of norms and standards in recent years increasingly used the factorial method, based on consideration of the factors which has an influence on their change in the planning period.

\section{References}

1. A. Ambartsumov, A. Sterlikov, 1000 market economy termins (Cron-press, Moscow, 1993)

2. G.L. Azoev, Competitiveness: analysis, strategy and practice. Moscow (Center of Economics and Marketing, Moscow, 1996) 
3. R.A. Fathutdinov, Strategic marketing (CJSC, Moscow, 2000)

4. V.F. Bogachev, The World of Economics and law 1, 7-15 (2012)

5. N.P. Veretennikov, R.G. Leont'ev, Regional'nye korporacii v sfere telekommunikacij: organizacionnyj aspect (Vladivostok, 1999)

6. A. Hayek, A. Friedrich, Individualism and Economic Order (Isograph, Moscow, 2000)

7. G.L. Kiperman, Market economics (Republic, Moscow, 1993)

8. I.M. Kirzner, Competition and Entrepreneurship (The University of Chicago Press, Chicago, 1973)

9. I.M. Lifits, Competitiveness of goods and services (Urait, Moscow 2009)

10. A. Marshall, Principles of Economics (Macmillan, London, 1920)

11. N.I. Lygina, I.R. Lyapina, Marketing of goods and service (Forum, Moscow, 2005)

12. N.S. Nosova, Competitive strategy of company or marketing methods of competitive fight (Dashkov \& Co, Moscow, 2009)

13. An.B. Mottaeva, As.B. Mottaeva, Int. Journal of Applied Engineering Research 1, 1023 (2015)

14. An.B. Mottaeva, As.B. Mottaeva, Int. Journal of Applied Engineering Research 1, 11 9 (2016)

15. E. Stein, N. Taskaeva, E. Chibisova, Procedia Engineering 165, 1410-1416 (2016)

16. A. Pimenova, S. Kuzmina, N. Morozova, A. Mottaeva, MATEC 73, 07018 (2016)

17. L.V. Nikolova, D.G. Rodionov, A.B. Mottaeva, Int. Journal of Economics and Financial Issues 6(S3), 1-7 (2016) 